ISSN 2079-9292

www.mdpi.com/journal/electronics

Article

\title{
Footwear and Wrist Communication Links using 2.4 GHz and UWB Antennas
}

\section{Domenico Gaetano ${ }^{1} *$, Patrick McEvoy ${ }^{1}$, Max J. Ammann ${ }^{1,2}$, Colm Brannigan ${ }^{3}$, Louise Keating ${ }^{3}$ and Frances Horgan ${ }^{3}$}

1 AHFR, Dublin Institute of Technology, Kevin Street, Dublin 8, Ireland; E-Mails: Patrick.Mcevoy@dit.ie (P.M.); max.ammann@dit.ie (M.J.A.)

2 CTVR, Dublin Institute of Technology, Kevin Street, Dublin 8, Ireland

3 School of Physiotherapy, Royal College of Surgeon of Ireland, 123, St. Stephen's Green, Dublin 2, Ireland; E-Mails: colmbrannigan@rcsi.ie (C.B.); lkeating@rcsi.ie (L.K.); fhorgan@rcsi.ie (F.H.)

* Author to whom correspondence should be addressed; E-Mail: domenico.gaetano@mydit.ie; Tel.: +353-1-402-4905.

Received: 19 February 2014; in revised form: 21 May 2014 / Accepted: 26 May 2014 / Published: 4 June 2014

\begin{abstract}
It is reported that wearable electronic devices are to be used extensively in the next generation of sensors for sports and health monitoring. The information obtained from sensors on the human body depends on the biological parameters, the measurement rate and the number of sensors. The choice of the wireless protocol depends on the required data rates and on system configurations. The communication link quality is achieved with narrowband technologies such as Bluetooth or Zigbee, provided that the number of sensors is small and data rates are low. However, real-time measurements using wideband channels may also be necessary. This paper reports narrowband link performance at $2.45 \mathrm{GHz}$ for comparison with two UWB channels centered at $3.95 \mathrm{GHz}$ and $7.25 \mathrm{GHz}$. A monopole antenna covering $2.45 \mathrm{GHz}$ and UWB is optimized for an on-body communication link between the footwear and the wrist. The cumulative distribution function of several path loss measurements is reported and compared for a subject standing and walking. Results show that the larger bandwidth in the UWB channel reduces fading and stabilizes the channel predictability.
\end{abstract}

Keywords: 2.4 GHz; UWB; Rician channel; on-body antenna 


\section{Introduction}

Wearable technologies are electronic devices located in everyday clothing and accessories. Nowadays, there is an increasing demand to monitor performance of various activities in sports [1], daily routines [2] and health care scenarios [3]. The goals include measurement of biological and physical parameters with subsequent processing for different applications. These wearable devices are required to be small to avoid user discomfort. They may be integrated in a belt [4], necklace [5], shirt [6] or shoes [7]. Normally the sensor position depends on the biological and physical parameters to be measured. Sensors are placed in footwear to measure various biological parameters, including plantar pressure [8], speed [9], walking and running gait [10]. These data are useful to monitor everyday activity, to detect gait abnormality [9] and to detect the onset of various medical conditions [11].

These sensors need to be simple and consume low power. Combining information from different on-body deployed sensors requires a smarter and more complex node. This hub is responsible for collecting all the information to be processed, simplifying it and ultimately displaying it to the final user. The position and the technology used in the communication link between the different nodes and the main hub is important for overall system reliability. The main hub is typically located at the waist area of the body $[12,13]$ which is equidistant to other on-body nodes thereby reducing the maximum communication distance over the whole body. It has been demonstrated that using directional antennas on footwear achieves equal or better performances than a waist-centric paradigm with omnidirectional antennas [14]. However, the expansion of advanced handheld devices such as smartphones and smartwatch is shifting the hub-centric scenario from waist to the hand area. This on-body area is critical because of the rapid changes of the body posture responsible for shadowing and multipath fading behavior. The communication link must be reliable during everyday activities, including walking.

Different technologies are already used in the communication layer in the $2.45 \mathrm{GHz}$ frequency band such as Bluetooth [15] and WiFi [16]. These technologies are well known and widely used in many systems. However, new emerging technologies have greater data rates and are more secure. Within this framework, UWB technologies are characterized by wider bandwidths, lower power consumption and smaller range in comparison to the narrowband systems. Because of these advantages, UWB is a promising technology for the development of Body Area Networks [17]. The antenna design must take the operational environment into consideration [18]. On-body scenarios are characterized by close proximity to high water-content and low water-content materials which can influence the antenna performance. Besides it is important to include body movement because of fading and shadowing.

In this paper a communication link between the footwear and the wrist is studied for three different frequency ranges for a subject while walking. The footwear can be a hub location or can relay footwear sensor information to a handheld device.

Performances for footwear located antennas should consider the rapid and repetitive movement of the foot for a walking/running subject and the close proximity to the ground. The performance of a monopole antenna on the toe cap is not impaired by the ground proximity because the foot behaves as a screen, decreasing the back lobe radiation.

An antenna is designed to cover the $2.4 \mathrm{GHz}$ and UWB bands and can be integrated with multimode transceivers to mitigate on-body multipath effects and to adjust the data rate to the particular request. 
In the first section of the paper the antenna performances are shown in the free space and in close proximity to the body. In the second section the three frequency ranges are compared for a subject walking using $\mathrm{S}_{21}$ measurements.

\section{Antenna Geometry and Free Space Performance}

A single-sided printed monopole antenna is easier to integrate on the surface of the upper part of the footwear or above the textile strips of a garment, without the requirement of another layer. An antenna optimized for this purpose is prototyped on a $0.2 \mathrm{~mm}$ single-sided FR4 layer and shown in Figure 1a. For simplicity the antenna is fed by coplanar waveguide (CPW) which is connected to a SMA connector and optimized for on-body performance from $2.4 \mathrm{GHz}$ to $10 \mathrm{GHz}$. The antenna size is $40 \times 50 \mathrm{~mm}^{2}$. A transition in the CPW is required for matching due to the connector flange. The width of the feed line and slot line under the connector is $1 \mathrm{~mm}$ and $1.2 \mathrm{~mm}$ respectively. Beyond the connector, these become $3.3 \mathrm{~mm}$ and $0.2 \mathrm{~mm}$ respectively. The antenna is then shaped with splined lines, resulting from the on-body optimization. The ground plane shape is also optimized to increase the bandwidth of the antenna with the dimension $\mathrm{GP}_{1}=13 \mathrm{~mm}, \mathrm{D}_{1}=1 \mathrm{~mm}$ and $\mathrm{D}_{2}=0.8 \mathrm{~mm}$. The parameters of the splines are given in Table 1.

Figure 1. (a) Antenna geometry; (b) comparison of simulated and measured $\mathrm{S}_{11}$ for the antenna in free space; (c) photo of the prototyped antenna.

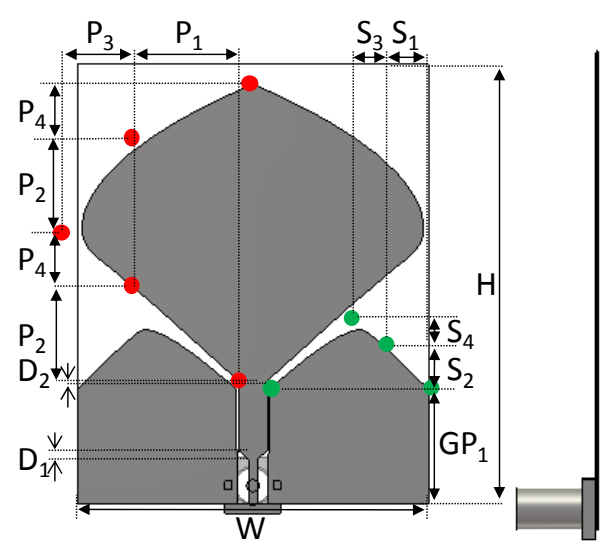

(a)

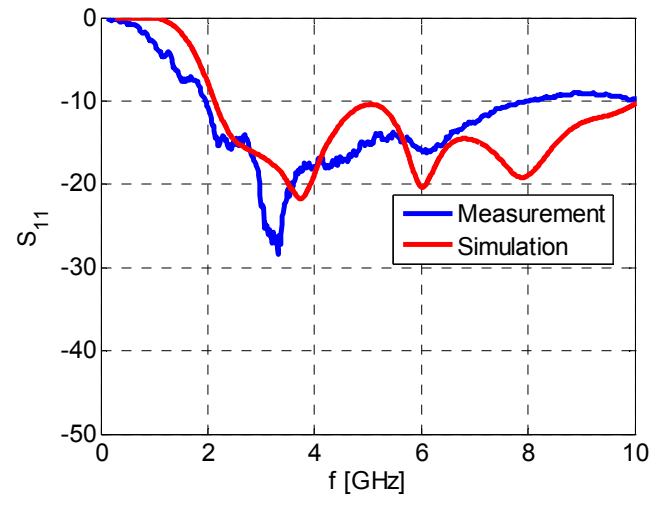

(b)

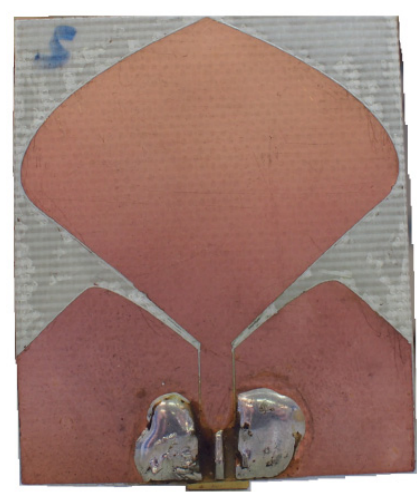

(c)

The antenna free-space $S_{11}$ is shown in Figure $1 b$. The simulated bandwidth of the antenna is $-10 \mathrm{~dB}$ matched across $2.1-10 \mathrm{GHz}$. In the measurement there is a shift of the lower $-10 \mathrm{~dB}$ frequency of $177 \mathrm{MHz}$. The measured $-10 \mathrm{~dB}$ bandwidth for the free space antenna is within the range of $2 \mathrm{GHz}$ to $8 \mathrm{GHz}$. The small disagreement between simulation and measurement is due to an imperfectly flat dielectric layer and non-uniform distance between the printed copper feed line on the dielectric of the CPW and the flange of the connector. A photograph of the prototyped antenna is shown in Figure 1c. 
Table 1. Parameters value of the spline.

\begin{tabular}{cccccc}
\hline \multicolumn{2}{c}{ Antenna [red points] } & & \multicolumn{2}{c}{ Ground [green points] } \\
\cline { 1 - 2 } \cline { 5 - 5 } Parameter & Dimension [mm] & & Parameter & Dimension [mm] \\
\hline$P_{1}$ & 12 & & $S_{1}$ & 5 \\
$P_{2}$ & 11 & & $S_{2}$ & 5 \\
$P_{3}$ & 8 & & $S_{3}$ & 4 \\
$P_{4}$ & 6 & & $S_{4}$ & 3 \\
\hline
\end{tabular}

\section{On-Body Antenna Performances}

In this section the antenna on-body performances are investigated for two different body locations: the footwear toe-cap and the wrist. The body model consists of voxel files representing the wrist and the foot. In the wrist model case the distance between the antenna and the body is equal to $5 \mathrm{~mm}$. For the footwear case the antenna is located next to the skin voxels. The voxel model of the foot is non-planar, so the distance between the antenna and the foot varies from $1 \mathrm{~mm}$ to $8.5 \mathrm{~mm}$. The foot and wrist models include different body tissues, such as skin, fat, muscle and bone. The electrical properties of these materials are frequency dependent [19].

The antenna located on the simulated voxel model and the electrical properties of the tissues are shown in Figure 2.

Figure 2. (a) On-body model; (b) Electrical properties of the human body materials (continuous line $\varepsilon_{1}$, dotted line $\varepsilon_{2}$ ).
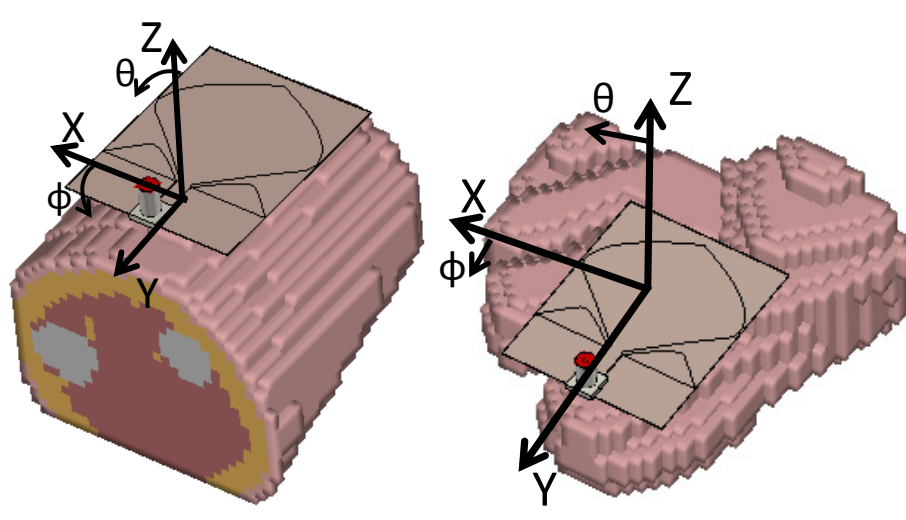

(a)

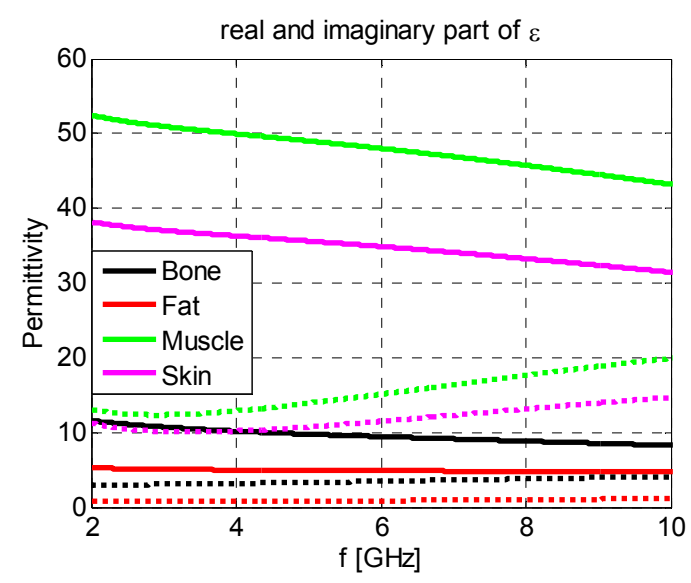

(b)

The voxel file resembles the shape of the human body parts and it reproduces the internal geometry. The voxel foot model is mostly composed of bones, characterized by small values of permittivity and losses. The voxel wrist model is mostly composed of high water-content material such as muscle, although there is a thin layer of skin and a thicker layer of fat closer to the antenna. A comparison between simulation and measurement of the antenna located on the footwear and on the wrist are shown in Figure 3. The shoe materials are not considered in the simulation model. The thin toe cap layer is negligible compared to the close proximity to the high dielectric constant and lossy body tissues.

The measured and simulated $\mathrm{S}_{11}$ of the wrist and toe-cap mounted antennas is less than $-8.5 \mathrm{~dB}$ across the band of interest. 
Figure 3. Comparison of measured and simulated $\mathrm{S}_{11}$ for wrist (a) and footwear (b).

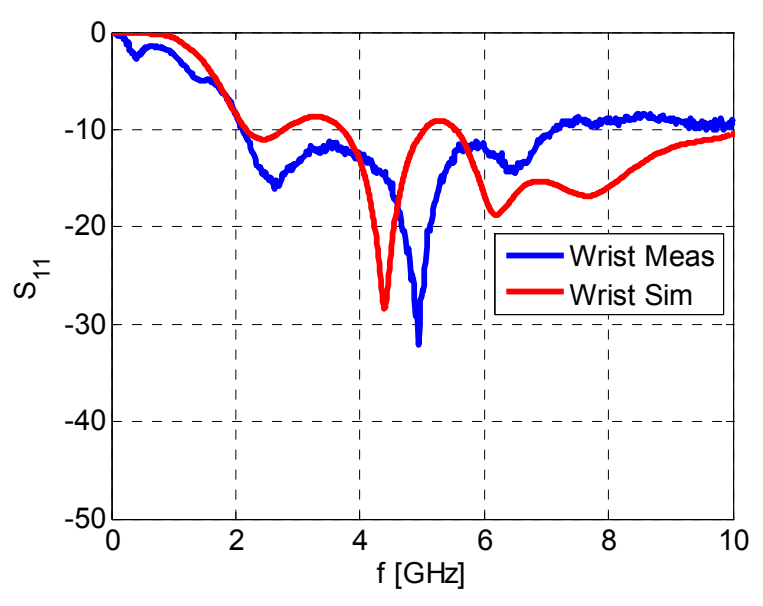

(a)

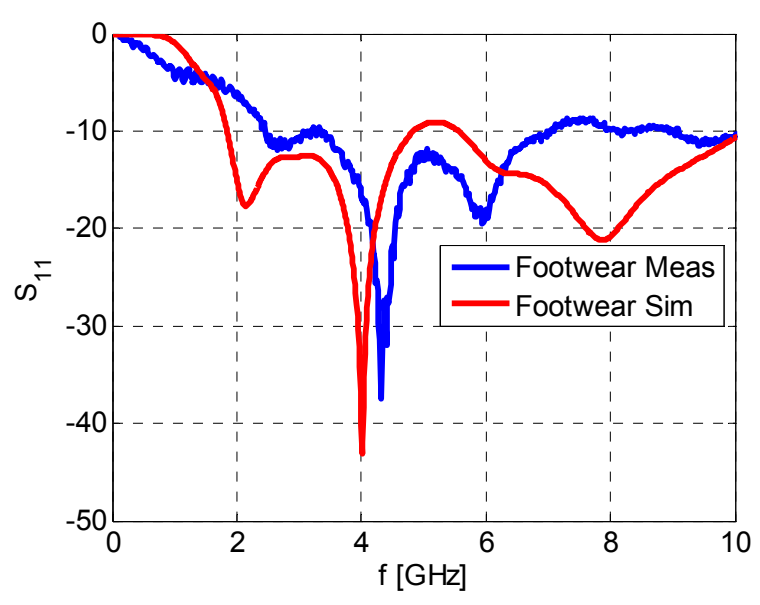

(b)

Small disagreements between simulation and measurement are due to differences between the voxel model shape and the actual human case. The antenna was perfectly centered on the wrist with human body tissue equally distributed below the antenna. The loading of the toes in the footwear case is not symmetrical due to the presence of air-spaces and the non-constant antenna-foot separation. The simulated radiation patterns are shown in Figures 4 and 5. The realized gain as a function of frequency is summarized in Table 2.

Figure 4. Realized gain patterns for monopole antenna on footwear for $\varphi=0^{\circ}$ and $\varphi=90^{\circ}$.
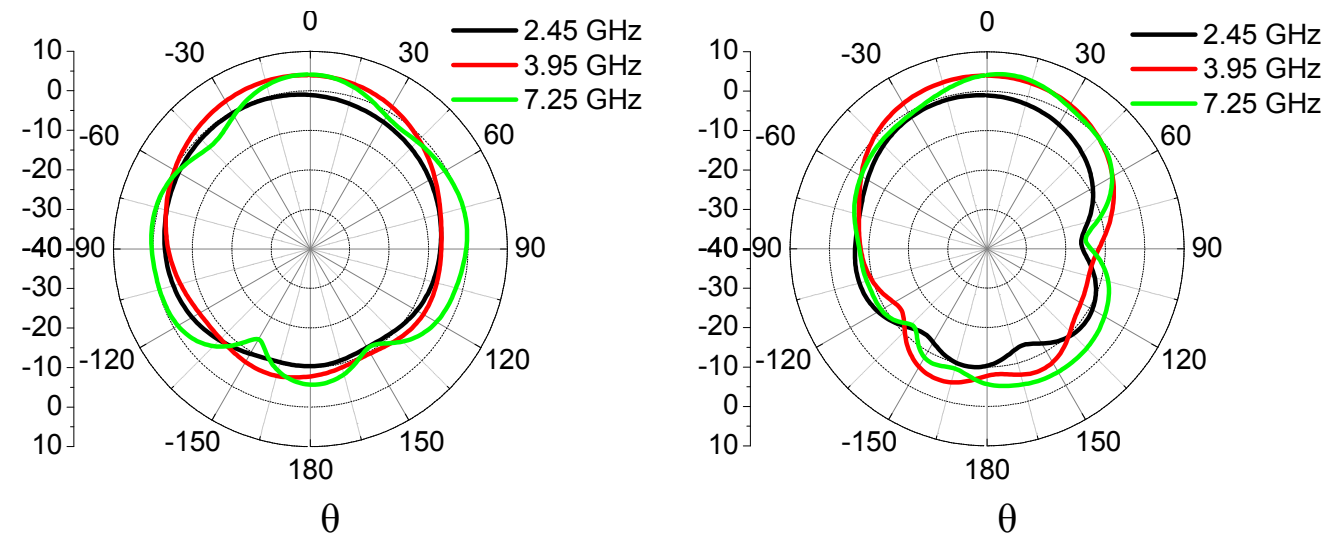

Figure 5. Realized gain patterns for monopole antenna on wrist for $\varphi=0^{\circ}$ and $\varphi=90^{\circ}$.
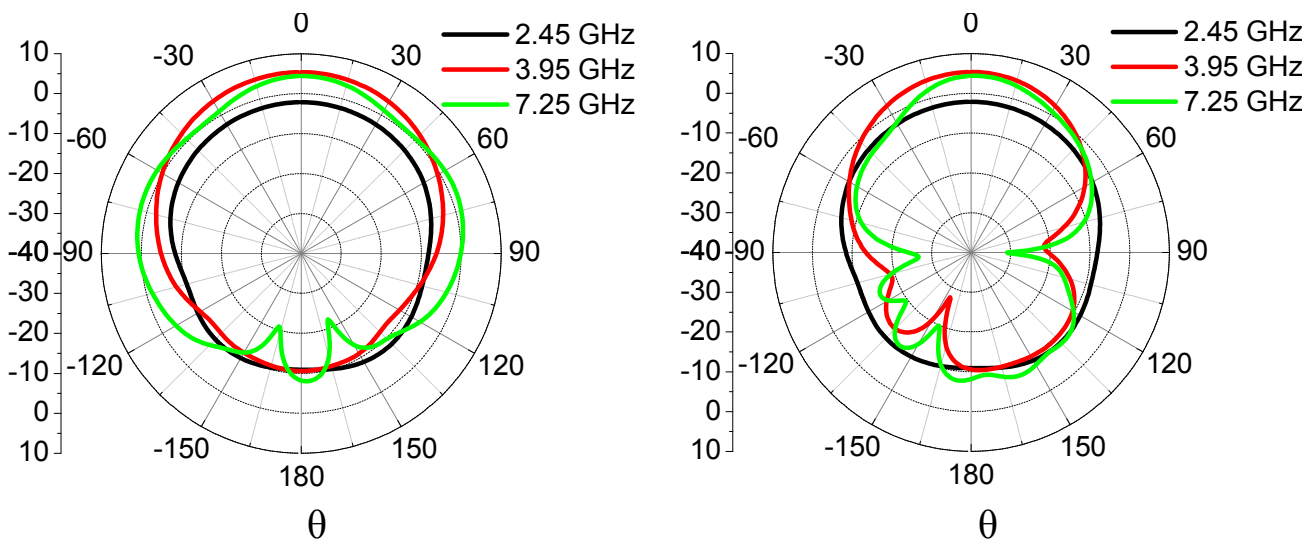
Table 2. Directivity parameters for the on-body antennas.

\begin{tabular}{|c|c|c|c|c|c|c|c|c|}
\hline \multirow[t]{2}{*}{$\begin{array}{c}\text { Frequency } \\
\text { [GHz] }\end{array}$} & \multicolumn{2}{|c|}{$\begin{array}{c}\text { Maximum realized } \\
\text { gain magnitude }[\mathrm{dBi}]\end{array}$} & \multicolumn{2}{|c|}{$\begin{array}{l}\text { 3-dB beamwidth } \\
\text { for } \varphi=0^{\circ}[\mathrm{deg}]\end{array}$} & \multicolumn{2}{|c|}{$\begin{array}{l}\text { 3-dB beamwidth } \\
\text { for } \varphi=90^{\circ}[\mathrm{deg}]\end{array}$} & \multicolumn{2}{|c|}{$\begin{array}{l}\text { Radiation } \\
\text { efficiency }\end{array}$} \\
\hline & Wrist & Footwear & Wrist & Footwear & Wrist & Footwear & Wrist & Footwear \\
\hline 2.45 & -2.09 & -0.16 & 131.3 & 131.9 & 86.6 & 84.3 & $21 \%$ & $30 \%$ \\
\hline 3.95 & 5.37 & 4.07 & 86.6 & 83.4 & 61.4 & 80.5 & $54 \%$ & $55 \%$ \\
\hline 7.25 & 4.41 & 4.46 & 57.1 & 42.7 & 44.3 & 46.1 & $65 \%$ & $64 \%$ \\
\hline
\end{tabular}

The antenna radiation efficiency increases with frequency because the electrical distance between the antenna and the body increases. The difference in the shapes of the radiation pattern for the footwear and the wrist locations is due to dissimilar body geometries and to the different positions of the antenna respect to the body. The antenna is characterized by the maximum realized gain for the $3.95 \mathrm{GHz}$ frequency for the wrist case. Considering a walking subject, the $3 \mathrm{~dB}$ beamwidth for $\varphi=90^{\circ}$ for the toe-cap mounted antenna is wide enough to cover the arm swing of the walking subject.

\section{Measurements}

The $\mathrm{S}_{21}$ was measured using a Rohde \& Schwarz ZVA 25 for a subject standing and walking. The measurements are made in a room $8.1 \times 7.9 \mathrm{~m}^{2}$ with furniture and reinforced concrete walls and floors. The person is walking along one side of the room as shown in Figure 6a. The first antenna is located on the right-side shoe toe-cap and the second antenna is located above the right wrist, as shown in Figure 7. Three different frequency bands are analyzed as shown in Figure 6b:

- $50 \mathrm{MHz}$ centered at $2.45 \mathrm{GHz}$

- $500 \mathrm{MHz}$ centered at $3.95 \mathrm{GHz}$

- $500 \mathrm{MHz}$ centered at $7.25 \mathrm{GHz}$

Figure 6. (a) Layout of the room; (b) investigated frequencies with bandwidth.

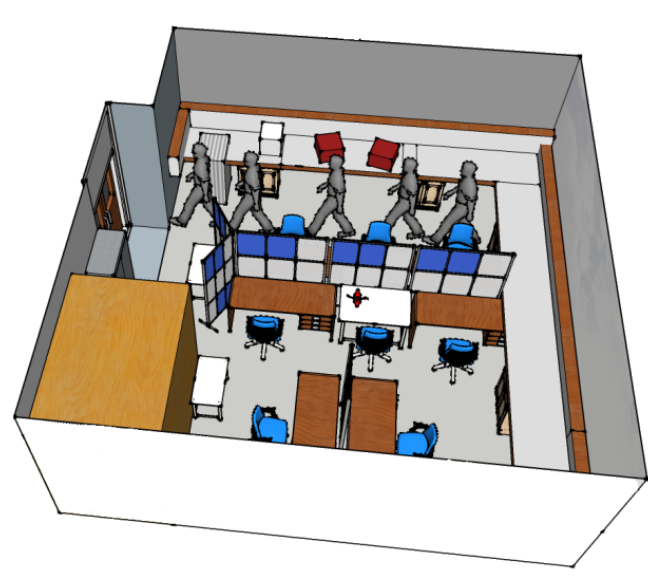

(a)

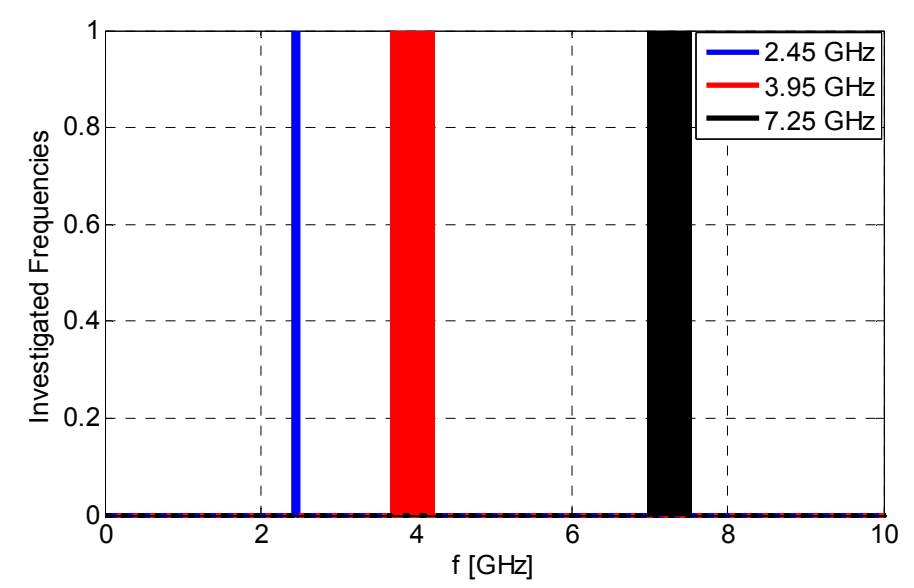

(b)

The three frequencies represent the centre frequencies for the narrowband and UWB physical layer for wireless BAN networks in IEEE 802.15.6. 
Figure 7. Walking subject with antennas on wrist and toe-cap footwear.
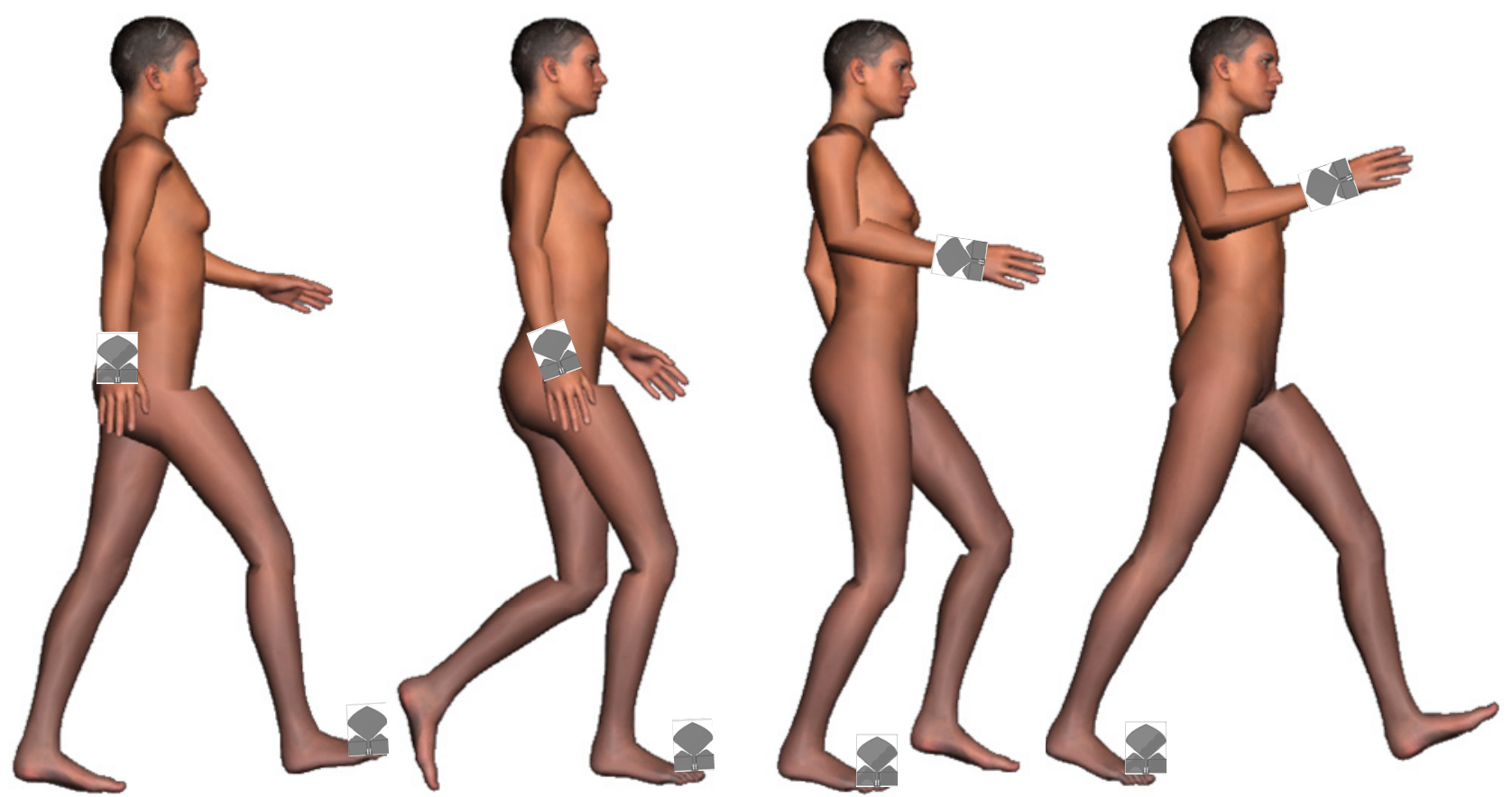

To avoid obstruction of the cables by the subject walking, the VNA was placed at the side of the room and the cables located behind the subject. In this way the cables trail the walking subject, without impacting on the gait. Photos of the measurement setup are shown in Figure 8.

Figure 8. Photos of the on-body antennas.

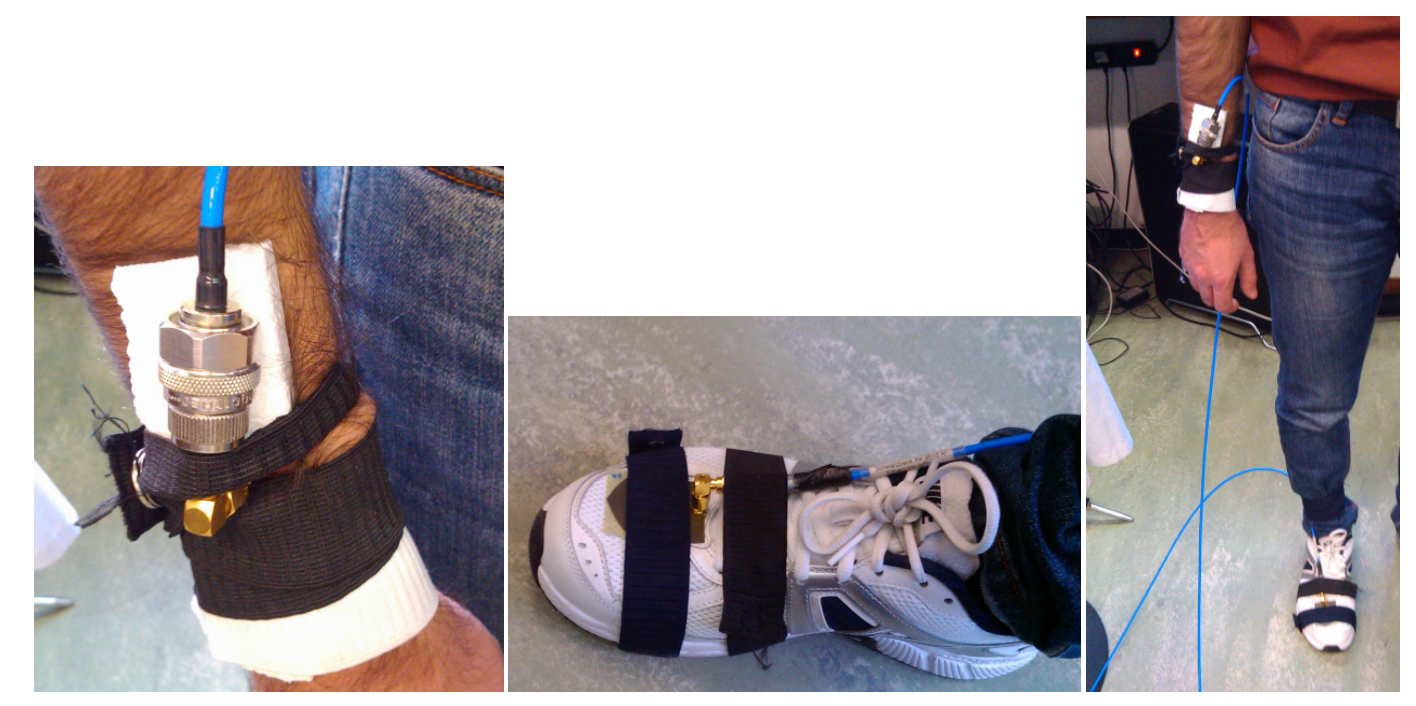

In total there are five measurements with 330 frequency sweep samples for a subject walking and standing. The first $10 \mathrm{~s}$ are related to a stationary subject at one side of the room. Then the subject walks to the other side of the room. Finally the subject stands still at the other side of the room. There is a measurement every $\sim 100 \mathrm{~ms}$. The total time for each measurement is $\sim 33 \mathrm{~s}$. The measurements were made on a subject of mass $70 \mathrm{~kg}$ and $1.75 \mathrm{~m}$ tall. Path loss results are displayed in terms of Cumulative Distribution Function (CDF) and compared with the Rician distribution using the Maximum Likelihood Estimation (MLE) criteria. 


\subsection{Narrowband Channel-2.45 GHz}

In this paragraph the results for the $2.45 \mathrm{GHz}$ narrowband channel is investigated. The link channel measured in the five campaigns of measurements as a function of time is shown in Figure 9a. For the first $10 \mathrm{~s}$, the variation in the channel is small (between $-59 \mathrm{~dB}$ and $-50 \mathrm{~dB}$ ). When the subject starts walking the $S_{21}$ oscillation increases, but remaining between $-67.8 \mathrm{~dB}$ and $-48 \mathrm{~dB}$. Finally the subject is standing in front of a wall, and the $\mathrm{S}_{21}$ is almost constant for each set of measurements. The CDF of the five measurements is shown in Figure 9b. The minimum and the maximum values of the five measurements are summarized in Table 3. Considering all the measurements, the maximum range is equal to $19 \mathrm{~dB}$. The CDF is compared with the MLE for the corresponding Rician Distribution, assuming that there is a main ray between the foot and the wrist.

Figure 9. (a) measured $\mathrm{S}_{21}$ for a subject walking; (b) CDF of the path loss for the five cases.

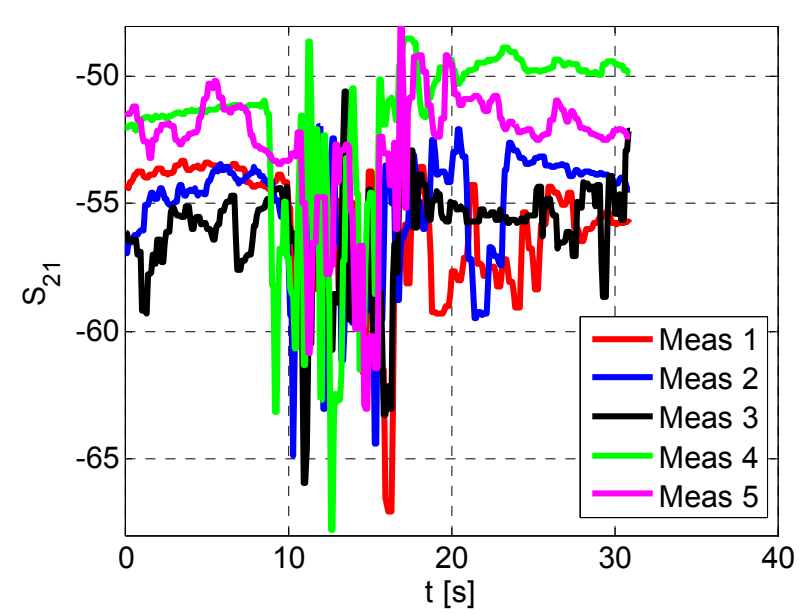

(a)

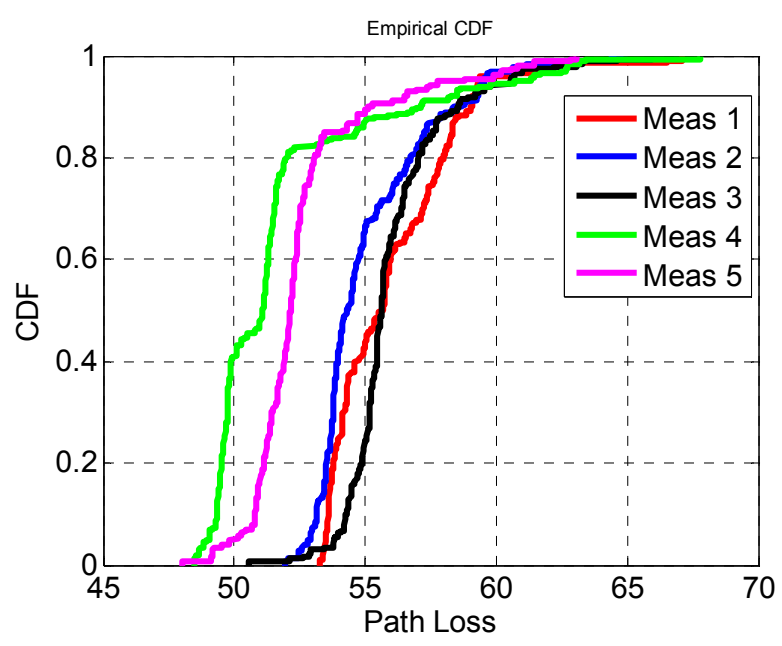

(b)

Table 3. K-factor estimation for the different measurements for the $2.45 \mathrm{GHz}$ channel.

\begin{tabular}{lccc}
\hline & Minimum path loss [dB] & Maximum path loss [dB] & K-factor [dB] \\
\hline Meas 1 & 53 & 67 & 9.16 \\
Meas 2 & 52 & 65 & 9.97 \\
Meas 3 & 50 & 66 & 10.5 \\
Meas 4 & 48 & 68 & 7.5 \\
Meas 5 & 48 & 63 & 9.7 \\
\hline
\end{tabular}

The K-factor of the Rician distribution is summarized in Table 3. All the measurements are characterized by a K-factor always greater than $7.5 \mathrm{~dB}$, evidencing the presence of a main component of the received signal greater than the scattered components. The range of K-factors spans from $7.5 \mathrm{~dB}$ to $10.5 \mathrm{~dB}$. The path loss is always smaller than $67 \mathrm{~dB}$.

\subsection{Lower UWB Channel $3.95 \mathrm{GHz}$}

In this section the results of the lower UWB channel are shown. The investigated centre frequency is $3.95 \mathrm{GHz}$ with $500 \mathrm{MHz}$ bandwidth. The $\mathrm{S}_{21}$ measurements of a walking subject as a function of the 
time, is shown in Figure 10a. The $S_{21}$ is almost constant for the stationary subject at the starting point and in front of the wall. When the subject is walking the $S_{21}$ oscillates with a greater range of values, with peaks of maximum $\mathrm{S}_{21}$ equal to $-51.89 \mathrm{~dB}$ and minima of $-57.23 \mathrm{~dB}$. The $\mathrm{CDF}$ of the five measurements is shown in Figure 10b.

Figure 10. (a) Measured $S_{21}$ for a walking subject; (b) CDF of the path loss for the five cases.

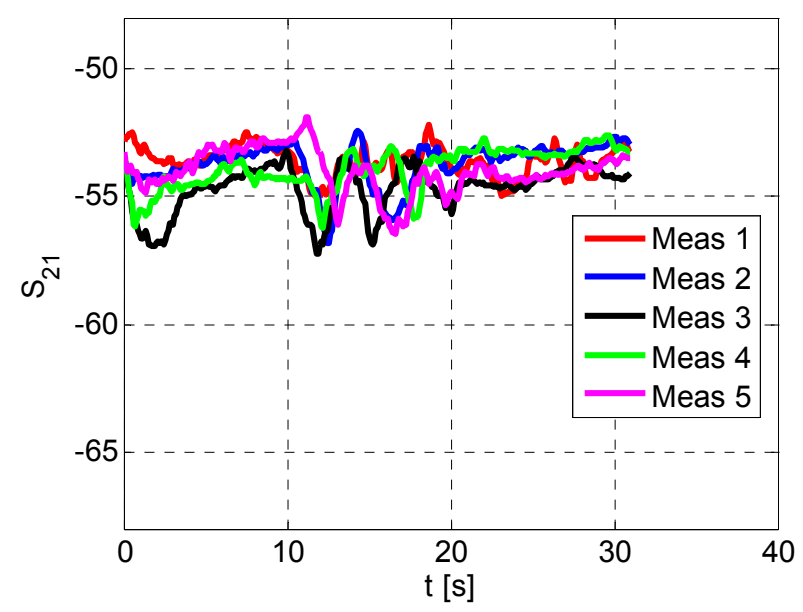

(a)

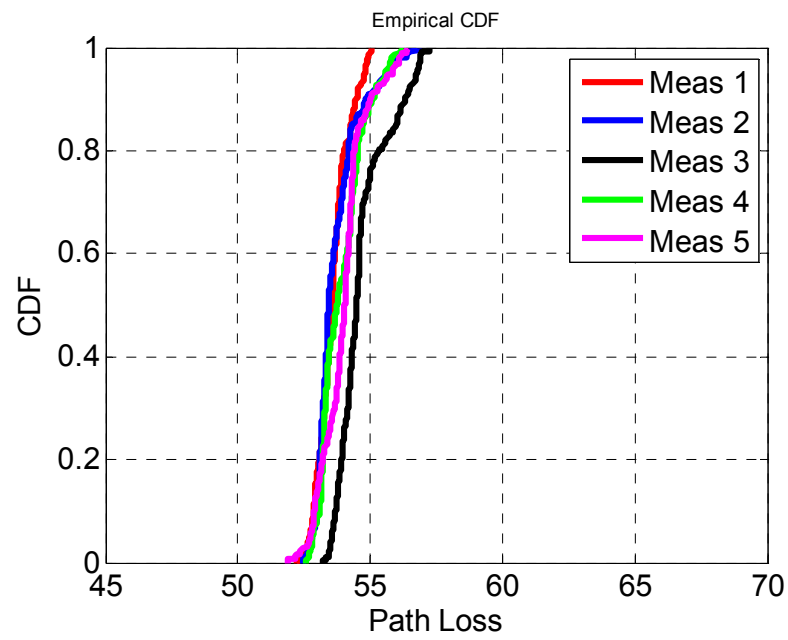

(b)

The CDF distributions for the measurements are very similar. Table 4 summarizes the minimum and maximum values and the $\mathrm{K}$-factor for the corresponding Rician distribution. The $\mathrm{K}$-factor for the $3.95 \mathrm{GHz}$ frequency range is always greater than 16.2, corresponding to a more directive link between the footwear and the wrist compared to the $2.45 \mathrm{GHz}$ case. This is also due to a greater antenna realized gain compared to the $2.45 \mathrm{GHz}$ case. The increased bandwidth decreases the fading, reducing the maximum path loss variation to $4 \mathrm{~dB}$. The greater K-factor compared to the narrowband channel can also be explained by the smaller antenna beamwidth, reducing reflected signals from the surrounding environment.

Table 4. K-factor estimation for the different measurements for the $3.95 \mathrm{GHz}$ channel.

\begin{tabular}{lccc}
\hline & Minimum path loss [dB] & Maximum path loss [dB] & K-factor [dB] \\
\hline Meas 1 & 52 & 52 & 20.5 \\
Meas 2 & 53 & 57 & 18.0 \\
Meas 3 & 53 & 57 & 16.2 \\
Meas 4 & 55 & 56 & 17.2 \\
Meas 5 & 52 & 57 & 17.3 \\
\hline
\end{tabular}

\subsection{Upper UWB Channel 7.25 GHz}

The performance for the upper UWB band is also investigated. The centre frequency is $7.25 \mathrm{GHz}$ with a $500 \mathrm{MHz}$ bandwidth. In Figure 11a the measured $S_{21}$ for the walking subject as a function of time are shown. As observed for previous cases, the $S_{21}$ is almost constant for the first $10 \mathrm{~s}$, with a $S_{21}$ value equal to $\sim-53.5 \mathrm{~dB}$. When the subject is walking, the $\mathrm{S}_{21}$ range remains between $-54.22 \mathrm{~dB}$ and $-51.56 \mathrm{~dB}$. Finally when the subject is stationary at the end of the room the $\mathrm{S}_{21}$ is almost constant and 
equal to $-53.75 \mathrm{~dB}$. The CDFs of the five measurements are shown in Figure $11 \mathrm{~b}$. In this case the measurements are much closer to each other. The measured path loss values and K-factors are summarized in Table 5. The K-factor is greater than the previous case and always greater than $20.9 \mathrm{~dB}$. The difference between the maximum and the minimum $\mathrm{K}$-factor is equal to $5.1 \mathrm{~dB}$.

Figure 11. (a) Measured $S_{21}$ for a walking subject; (b) CDF of the path loss for the five cases.

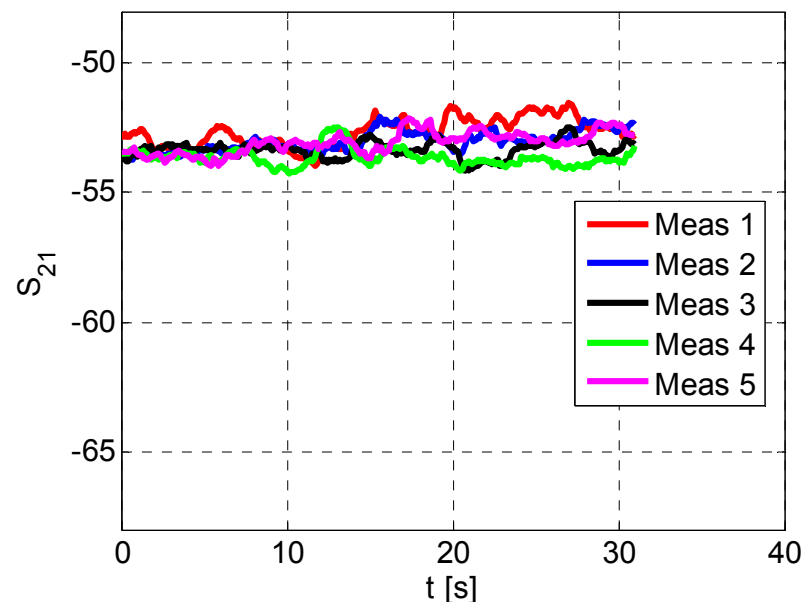

(a)

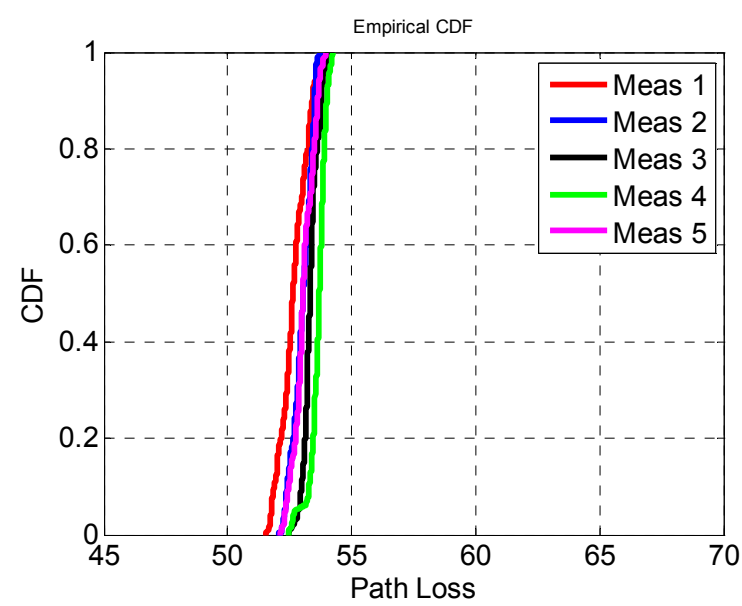

(b)

Table 5. K-factor estimation for the different measurements for the $7.25 \mathrm{GHz}$ channel.

\begin{tabular}{lccc}
\hline & Minimum path loss [dB] & Maximum path loss [dB] & K-factor [dB] \\
\hline Meas 1 & 52 & 54 & 20.9 \\
Meas 2 & 52 & 54 & 23.7 \\
Meas 3 & 52 & 54 & 26.0 \\
Meas 4 & 52 & 54 & 24.9 \\
Meas 5 & 52 & 54 & 23.3 \\
\hline
\end{tabular}

As expected, the $\mathrm{K}$-factor is greater than the previous cases. Although the maximum realized gain is less than the $3.95 \mathrm{GHz}$ case, the beamwidth of the antenna is smaller, resulting in a decreased signal scattering in the surrounding environment. The minimum path loss values are similar to the $3.95 \mathrm{GHz}$ because of the greater realized gain for the footwear antenna.

\section{Conclusions}

The $\mathrm{S}_{21}$ link between the wrist and footwear toe-cap is reported for a subject standing and walking. A monopole antenna is optimized for different on-body locations at $2.45 \mathrm{GHz}, 3.95 \mathrm{GHz}$ and $7.25 \mathrm{GHz}$. The results are summarized in terms of Cumulative Distribution Functions and the Maximum Likelihood Estimation criteria are used for K-factor parameter fit to a Rician distribution.

In the subject standing pose, the $S_{21}$ remains persistent for each of the three frequencies. When the subject is walking, the $S_{21}$ varies rapidly with lower $S_{21}$ values for lower frequencies. This is attributed to channel fading and shadowing by the hand during the arm swing motion associated with walking. At the lower frequency, the fading is more noticeable because the selected channel is narrowband.

The UWB channels are an easier fit to a Rician distribution, with small changes of the K-factor. In the $2.45 \mathrm{GHz}$ case, the Rician K-factor is $\sim 10 \mathrm{~dB}$ lower than that for the UWB channels. This is due to 
the larger beamwidth at $2.45 \mathrm{GHz}$ which increases the signal scattering from surrounding environment. The minimum path loss for each of the UWB channels is the same due to higher antenna efficiency. The $7.25 \mathrm{GHz}$ channel is characterized by the largest K-factor due to its smaller beamwidth. The communication link complies with the standard for each of the measured cases for a subject standing and walking.

Further work will consider the receiving node in different body locations; hence it will establish the optimum frequency band for different body locations. The antenna will be tested in an outdoor environment and with different transceivers to mitigate cable effects.

\section{Acknowledgments}

This work was supported by the Science Foundation Ireland under Grant 09/IN.1/I2652.

\section{Conflicts of Interest}

The authors declare no conflict of interest.

\section{References}

1. Ermes, M.; Pärkka, J.; Mantyjarvi, J.; Korhonen, I. Detection of daily activities and sports with wearable sensors in controlled and uncontrolled conditions. IEEE Trans. Inf. Technol. Biomed. 2008, 12, 20-26.

2. Hu, Y.; Stoelting, A.; Wang, Y.; Zou, Y.; Sarrafzadeh, M. Providing a cushion for wireless healthcare application development. IEEE Potentials 2010, 29, 19-23.

3. Crumley, G.C.; Evans, N.E.; Scanlon, W.G.; Burns, J.B.; Trouton, T.G. The design and performance of a $2.5-\mathrm{GHz}$ telecommand link for wireless biomedical monitoring. IEEE Trans. Inf. Technol. Biomed. 2000, 4, 285-291.

4. Zuckerwar, A.J.; Pretlow, R.A.; Stoughton, J.W.; Baker, D.A. Development of a piezopolymer pressure sensor for a portable fetal heart rate monitor. IEEE Trans. Biomed. Eng. 1993, 40, 963-969.

5. Vidojkovic, M.; Huang, X.; Harpe, P.; Rampu, S.; Zhou, C.; Huang, L.; van de Molengraft, J.; Imamura, K.; Busze, B.; Bouwens, F.; et al. A 2.4 GHz ULP OOK Single-Chip Transceiver for Healthcare Applications. IEEE Trans. Biomed. Circuits Syst. 2011, 5, 523-534.

6. Nemati, E.; Deen, M.J.; Mondal, T. A Wireless Wearable ECG Sensor for Long-Term Applications. IEEE Commun. Mag. 2012, 50, 36-43.

7. Sazonov, E.S.; Fulk, G.; Hill, J.; Schutz, Y.; Browning, R. Monitoring of posture allocations and activities by a shoe-based wearable sensor. IEEE Trans. Biomed. Eng. 2011, 58, 983-990.

8. In-shoe Plantar Pressure Analysis. Available online: http://www.tekscan.com $/ \mathrm{medical} / \mathrm{system}$ fscan1.html (accessed on 27 May 2014).

9. Bamberg, S.J.M.; Benbasat, A.Y.; Scarborough, D.M.; Krebs, D.E.; Paradiso, J.A. Gait analysis using a shoe-integrated wireless sensor system. IEEE Trans. Inf. Technol. Biomed. 2008, 12, 413-423. 
10. Morris, S.J.; Paradiso, J.A.; Development, A.H. Shoe-Integrated Sensor System For Wireless Gait Analysis and Real-Time Feedback. In Proceedings of the Second Joint EMBS/BMES Conference, Houston, TX, USA, 23-26 October 2002; pp. 2468-2469.

11. Mariani, B.; Jim, C. On-Shoe Wearable Sensors for Gait and Turning Assessment of Patients with Parkinson's Disease. IEEE Trans. Biomed. Eng. 2013, 60, 155-158.

12. Cotton, S.L.; Conway, G.A.; Scanlon, W.G. A Time-Domain Approach to the Analysis and Modeling of On-Body Propagation Characteristics Using Synchronized Measurements at $2.45 \mathrm{GHz}$. Trans. Antennas Propag. 2009, 57, 943-955.

13. Nechayev, Y.I.; Hall, P.S.; Hu, Z.H. Characterisation of narrowband communication channels on the human body at $2.45 \mathrm{GHz}$. IET Microwa. Antennas Propag. 2010, 4, 722-732.

14. Gaetano, D.; Sipal, V.; McEvoy, P.; Ammann, M.J.; Brannigan, C.; Keating, L.; Horgan, F. Footwear-centric body area network with directional UWB antenna. IEEE Electron. Lett. 2013, $49,860-861$.

15. 802.15.1-2002-IEEE Standard for Telecommunications and Information Exchange Between Systems-LAN/MAN_Specific Requirements-Part 15: Wireless Medium Access Control (MAC) and Physical Layer (PHY) Specifications for Wireless Personal Area Networks (WPANs); The Institute of Electrical and Electronics Engineers, Inc.: New York, NY, USA, 2002.

16. 802.11a-1999-IEEE Standard for Information Technology-Telecommunications and Information Exchange Between Systems-Local and Metropolitan Area Networks-Specific Requirements-Part 11: Wireless LAN Medium Access Control (MAC) and Physical Layer (PHY) Specifications; The Institute of Electrical and Electronics Engineers, Inc.: New York, NY, USA, 1999.

17. Alomainy, A.; Sani, A.; Rahman, A.; Santas, J.G.; Hao, Y. Transient characteristics of wearable antennas and radio propagation channels for ultrawideband body-centric wireless communications. Trans. Antennas Propag. 2009, 57, 875-884.

18. Gaetano, D.; McEvoy, P.; Ammann, M.J.; Browne, J.E.; Keating, L.; Horgan, F. Footwear Antennas for Body Area Telemetry. Trans. Antennas Propag. 2013, 61, 4908-4916.

19. Gabriel, S.; Lau, R.W.; Gabriel, C. The dielectric properties of biological tissues: III. Parametric models for the dielectric spectrum of tissues. Phys. Med. Biol. 1996, 41, 2271-2293.

(C) 2014 by the authors; licensee MDPI, Basel, Switzerland. This article is an open access article distributed under the terms and conditions of the Creative Commons Attribution license (http://creativecommodraig McEvoyns.org/licenses/by/3.0/). 